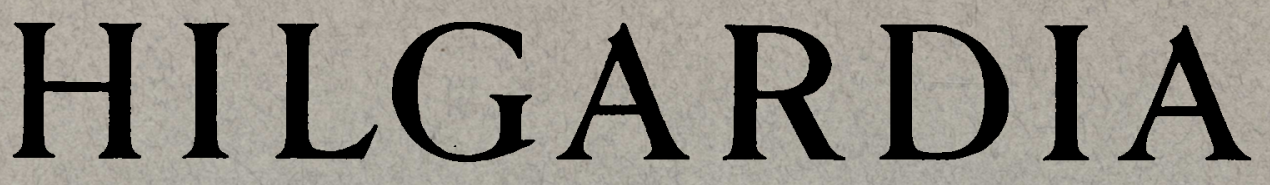

A Journal of Agricultural Science Published by the California Agricultural Experiment Station

EFFECT OF ZINC APPLICATIONS ON THE CROP OF GRAPEFRUIT TREES AFFECTED WITH MOTTLE-LEAF

\author{
E. R. PARKER
}




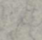

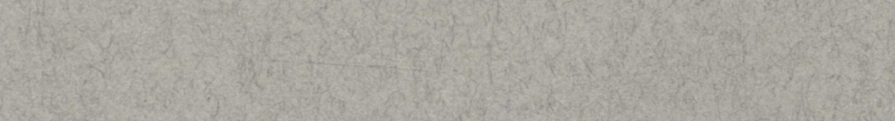

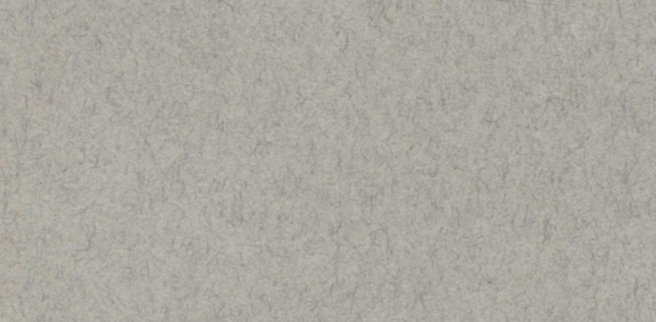

t (x) 


\title{
$\begin{array}{lllllllll}H & \text { I } & \text { L } & G & A & R & D & \text { I } & A\end{array}$
}

A Journal of Agricultural Science Published by

the California Agricultural Experiment Station

VoL. 11

DECEMBER, 1937

No. 2

\section{EFFECT OF ZINC APPLICATIONS ON THE CROP OF GRAPEFRUIT TREES AFFECTED \\ WITH MOTTLE-LEAF ${ }^{1,2}$}

\author{
E. R. PARKER ${ }^{3}$
}

\section{INTRODUCTION}

The SUPERFICIAL EFFECTS of mottle-leaf are readily apparent in the character of the foliage and in the vigor of citrus trees (Fawcett, 1936). ${ }^{4}$ The reduced size of individual leaves and the retarding of growth causes an obvious decrease in leaf area. According to Reed and Dufrénoy (1935), the condition of partial chlorosis involves a reduction in the number of chloroplasts and in the photosynthetic capacity of the leaves.

Such abnormalities might be expected to alter the carbohydrate metabolism of plants and to affect their reproductive activities. In the case of citrus, such an effect might result in a decreased yield and possibly in an effect on the quality of the fruit. In extreme cases of mottle-leaf, these effects are clearly evident on casual inspection. Not only is the crop light, but fruits produced on severely affected branches are small and abnormal; the nature of the abnormalities varies with the species of citrus observed. Where trees are slightly to moderately affected with mottle-leaf, however, it is difficult to tell by casual observation what, if any, influence this disorder has on the amount and quality of the fruit produced.

The development in recent years of a remedy for mottle-leaf makes it possible to determine the effect of the disorder in the less severe and

${ }^{1}$ Received for publication July 12, 1937.

${ }^{2}$ Paper No. 381, University of California Citrus Experiment Station and Graduate School of Tropical Agriculture, Riverside, California.

${ }^{3}$ Assistant Horticulturist in the Experiment Station.

${ }^{4}$ See Literature Cited at the end of the paper for complete data on citations, which are referred to in the text by author and date of publication. 
more frequently found eases. The purpose of this paper is to outline the results of studies made on the effect of mottle-leaf on the crops of rather typical grapefruit trees (Citrus paradisi Macfadyen), and to determine the yield responses of such trees to treatment. Data are also included as to the effects of mottle-leaf on the fruit of severely affected grapefruit trees.

The discovery of the effect of zine applications on characteristic disorders of trees by Chandler, Hoagland, and Hibbard (1931), and later independently by others, suggested that this element might have a relation to mottle-leaf of citrus trees. That this is a fact was demonstrated by Chandler, Hoagland, and Hibbard (1931, 1932), by Johnston (1933), coöperating with them, by Mowry and Camp (1934), and by Parker (1934). Practical methods of treating citrus trees have been developed (Johnston, 1934, and Parker, 1934, 1936).

The application to the foliage of sprays consisting of relatively insoluble zinc compounds suspended in water has resulted in the greening of old mottled foliage, in an increase in vigor of new growth, and in the production of normal foliage. In one instance Reed and Parker (1936) have measured the effect of increased vigor on leaf size and shoot growth. In severe cases the recovery of the trees results in clearly obvious increased yield and improved fruit quality. In the case of Washington Navel orange trees affected with mottle-leaf, Parker (1937) has shown an increase in yield after zine treatment, while Johnston (1936) has reported an increase in fruit size and a decrease in variability of fruit size of Valencia and Washington Navel oranges as a result of treatment.

\section{PROCEDURE}

The trees used for the experiments reported herein are located in the fertilizer plots at the University of California Citrus Experiment Station. The plan of these trials, reported by Batchelor, Parker, and McBride (1928), involves the use of alternate rows as guard rows for the fertilizer plots. In each guard row grapefruit trees alternate with Valencia oranges. There are five grapefruit trees in each row. In all, 209 rows in ten parallel blocks are involved.

In March, 1934, the degree of mottling in the grapefruit of this planting was rather typical of that commonly found in commercial orchards. However, the severity of mottle-leaf varied in different rows, apparently having been influenced by the fertilizer treatments to which each row had been subjected, since the trees in the same row were similar in condition. 
During the period March 9 to 15, 1934, when the earliest blossoms were beginning to show white petals, the east three of the five grapefruit trees in each guard row were sprayed with a mixture containing 10 pounds $\mathrm{ZnSO}_{4} \cdot 7 \mathrm{H}_{2} \mathrm{O}, 5$ pounds $\mathrm{Ca}(\mathrm{OH})_{2}$ (commercial materials), and 4 ounces of powdered blood-albumin spreader in 100 gallons of water. The blood albumin had been previously found to be without effect on mottle-leaf. A few individual grapefruit trees in the planting had been experimentally treated with zine compounds previous to 1934 with satisfactory effects on their foliage and growth. Such trees are included among the treated trees of this experiment. A few trees, abnormal for other reasons than mottle-leaf, were omitted from consideration.

The individual tree yields (volume basis) for 1933-34, the year prior to the beginning of the experiment, have been used to adjust, by Fisher's (1936) methods of covariance, the experimental yields in those parts of the study where small populations and inadequate replication are involved. Although this preliminary crop was not harvested until July, 1934, the fruit was presumably fully sized at the time of treatment in March, 1934, and it is believed that zine treatment at that time did not measurably affect the value of such adjustment.

The trees under observation as to the effect of zine treatment in the crop year 1934-35 were harvested in two groups. One group included only two rows, the trees of which were in the spring of 1934 much more severely affected with mottle-leaf than the rest of the orchard. The other group included the remainder of the orchard, which was moderately affected. In the former case, records of yields of individual trees and detailed notes on the fruit characteristics were obtained. The second group of the orchard was harvested separately, individual tree yields and the total weight of fruit for the zinc-treated and control trees being obtained. All the fruits from zinc-treated and control trees of this group were sized and graded separately in a commercial manner. ${ }^{5}$

\section{EFFECT OF MOTTLE-LEAF ON CROP OF MODERATELY AFFECTED GRAPEFRUIT TREES : THE RESPONSE TO ZINC TREATMENT}

With the exception of the two worst rows in the orchard, the grapefruit trees under experiment were only moderately affected with mottleleaf. The mean number of affected leaves was probably 30 to 40 per cent of the total. Some trees had a small proportion of mottled leaves, while on the worst trees of this group perhaps 60 per cent of the leaves

\footnotetext{
${ }^{5} \mathrm{I}$ am indebted to Mr. E. Hagen, Manager of the Monte Vista Citrus Association, Riverside, for grading the fruit.
} 
exhibited the partial chlorosis or decreased leaf size typical of the disorder. Few trees showed any dying-back of the terminals. The results of zinc treatment indicated, however, that the degree of mottling affected the crop to an important extent.

The yield of the 1934-35 crop was noticeably increased by zinc treatment in March, 1934. Table 1 shows that the number of pounds per tree was increased 19.9 per cent, and number of field boxes harvested

TABLE 1

Effect of Zinc Treatment of Graperruit Trees in March, 1934, on the 1934-35 CROP

\begin{tabular}{|c|c|c|c|c|}
\hline & Zinc-treated & Untreated & $\begin{array}{l}\text { Difference } \\
\text { (col. 1 - } \\
\text { col. 2) }\end{array}$ & $\begin{array}{c}\text { Increase (t) } \\
\text { or } \\
\text { decrease (-) }\end{array}$ \\
\hline & 1 & $\mathscr{2}$ & 3 & 4 \\
\hline & & & & per cent \\
\hline $\begin{array}{l}\text { Total number of trees in } 10 \text { blocks........... } \\
\text { Number of field boxes per tree....... }\end{array}$ & $\begin{array}{r}649 \\
9.89\end{array}$ & $\begin{array}{r}402 \\
8.23\end{array}$ & $\because \ldots$ & $\ldots \ldots$ \\
\hline Pounds of fruit per tree $\ldots \ldots \ldots \ldots \ldots \ldots \ldots$ & 408.63 & 340.87 & 67.76 & +19.9 \\
\hline Total number of fruits per tree......... & 624.37 & 546.72 & 77.65 & +14.2 \\
\hline Fruits of Fancy and Choice grades, per tree... & 427.21 & 281.10 & 146.11 & +52.0 \\
\hline Fruits of Fancy and Choice grades, packable & & & & \\
\hline sizes, per tree $\ldots \ldots \ldots \ldots \ldots \ldots \ldots$ & 405.85 & 249.13 & 156.72 & +62.9 \\
\hline Number of fruits per field box... & 63.16 & 66.42 & -3.26 & -4.9 \\
\hline
\end{tabular}

20.2 per cent. At the same time, the number of fruits per tree was increased only 14.2 per cent. That the fruit harvested from the zinctreated trees was larger in average size is indicated by the mean number of fruits per field box, which was decreased 4.9 per cent.

The effect of treatment on size of fruit is further indicated in figure 1 , which shows the mean number per tree of fruits of each packing-house size. It is noticeable that the treatment caused an increase in the number of large-sized fruits picked from an average tree. At the same time, there resulted a decrease in the number of small fruits. Sizes 64 to 150, inclusive, per packed box are the most marketable grapefruits. In 1935 these were the only sizes sufficiently in demand to warrant packing. Small fruits were sold locally, unpacked and at lower prices.

In the packing-house, grapefruits are customarily segregated into four grades : Fancy, Choice, Standard, and culls, the latter two grades being disposed of without packing. The numbers of fruits (for average trees) of each grade harvested from the zinc-treated and from the untreated trees are shown in figure 2. A noticeable improvement in the grades of the fruits was observed as a result of zinc treatment, the number of Fancy and Choice fruits being increased and the number of 


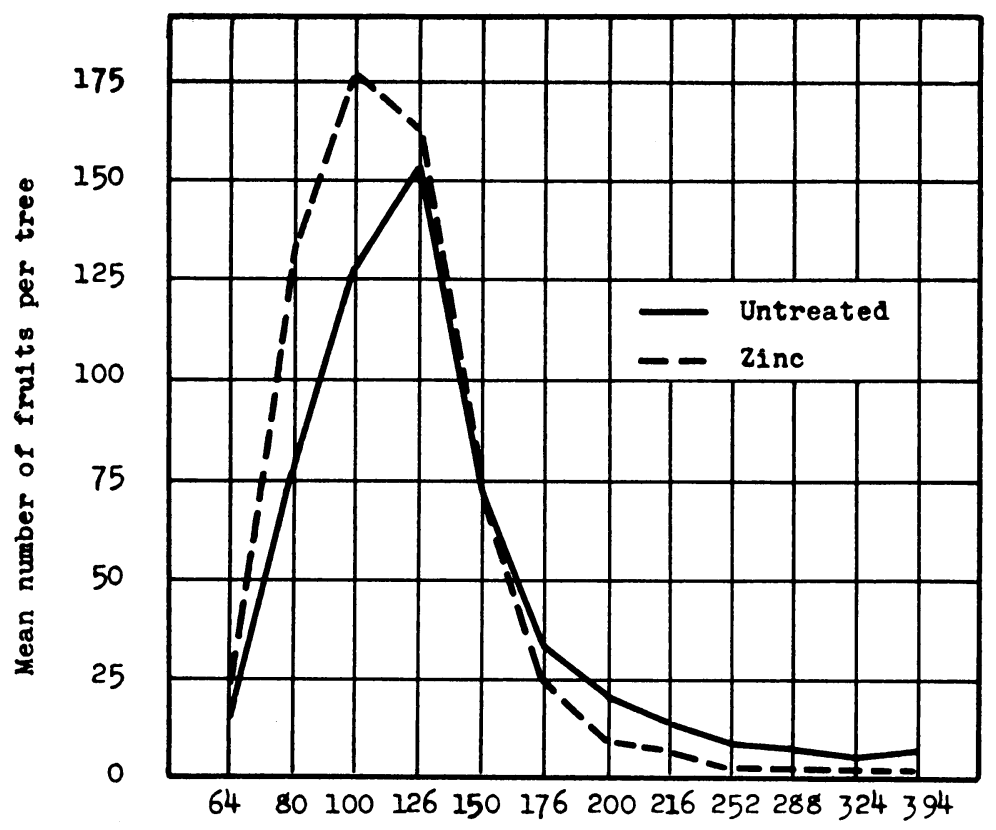

Number of frults per packing box

Fig. 1.-Distribution of fruit sizes; grapefruit, 1934-35 season.

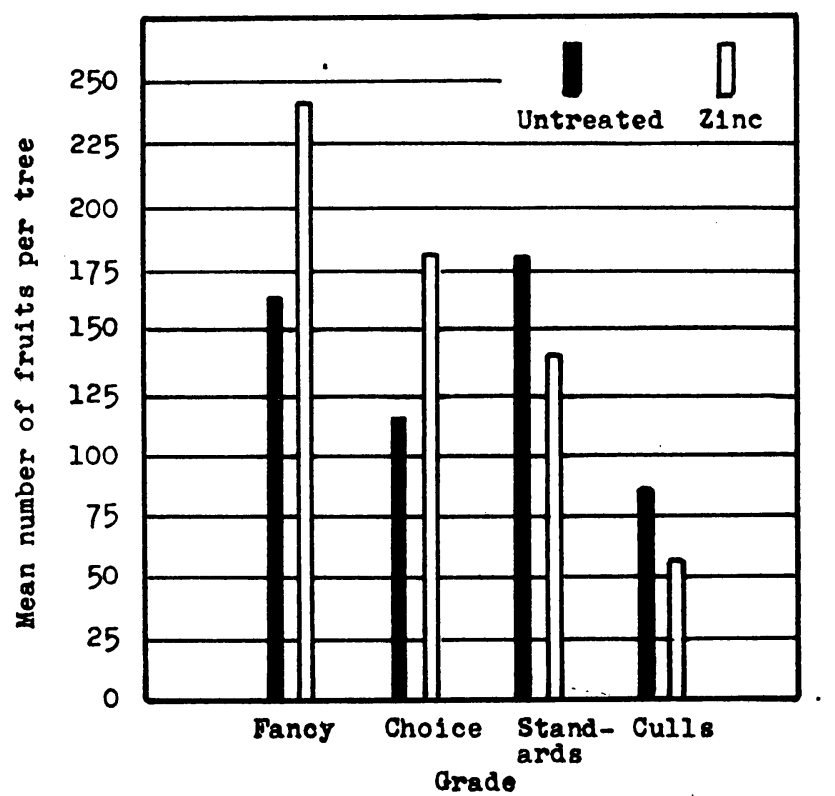

Fig. 2.-Mean number of fruits per tree of each packinghouse grade; grapefruit, 1934-35 season. 
unpackable fruits being decreased. Only 51.4 per cent of the erop of the untreated trees graded Fancy and Choice, while 68.4 per cent of the fruit harvested from treated trees was so graded. Because of the increased number of fruits harvested per tree, however, the total number of fruits of these desirable grades was increased 52.0 per cent as a result of zine treatment. Figure 2 shows that a part of this increase was due to a reduction of the number of fruits of inferior grades.

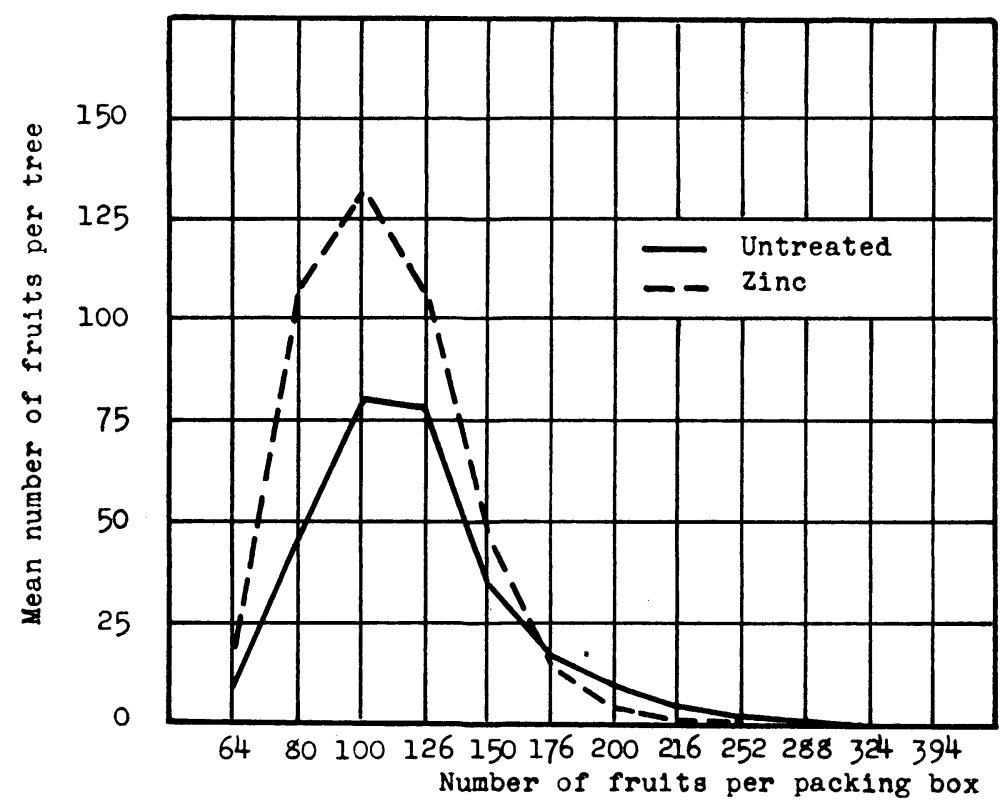

Fig. 3.-Distribution of size of fruit which graded Fancy and Choice; grapefruit, 1934-35 season.

Not only the number, but also the size distribution, of fruits which grade as Fancy and Choice is of great economic importance. The frequency distribution of such fruits is given on an average-tree basis in figure 3. It is obvious that the most marked increase in number of Fancy and Choice fruits occurred in the desirable large sizes. The total number per tree of fruits of packable sizes (64-150, inclusive, per box) and grades (Fancy and Choice) was found to be 45.6 per cent of all fruit for average untreated trees and 65.0 per cent for average treated trees. Owing to the increase in crop due to treatment, however, an increase of 62.9 per cent in the number of desirable fruits resulted from zinc applications.

Such large increases in yield and in the number of packable fruits 
are reflected in the returns for the fruit. When this fruit was marketed, the returns were at the following rates per packed fruit : ${ }^{6}$

$\begin{array}{crr}\text { Fruit size } & \text { Faney grade } & \text { Choice grade } \\ 64 & \$ 0.011027 & \$ 0.005463 \\ 80 & .013388 & .007719 \\ 100 & .010140 & .004829 \\ 126 & .006214 & .001504 \\ 150 & \$ 0.004393 & \$ 0.001557\end{array}$

These rates are low, owing to the heavy general crop of 1935 . However, the marked variation in prices paid for fruits of various sizes and grades is apparent. At these prices, the gross returns delivered at the packing-house for the packed fruit were, for zinc-treated trees, $\$ 2.98$ per tree; and for untreated trees, $\$ 1.72$ per tree.

To obtain the total gross return for fruit delivered to the packinghouse, the receipts for the sale of unpacked fruit must be added to these figures. The cost of harvesting and delivering to the packing-house must then be deducted to obtain the net value of the fruit on the trees.

TABLE 2

Analysis of Variance of Adjusted Yields in 1934-35 of the Grapefruit Trees LEAST A FFECTED BY MotTtLE-LEAF*

\begin{tabular}{|c|c|c|c|}
\hline Source of variation & $\begin{array}{l}\text { Degrees of } \\
\text { freedom }\end{array}$ & Mean squares & $F \dagger$ \\
\hline Total..... & 129 & 3.7112 & $\ldots \ldots$ \\
\hline Between rows $\ldots \ldots \ldots \ldots \ldots \ldots \ldots \ldots \ldots \ldots$ & 25 & 4.8663 & $\ldots \ldots$ \\
\hline Between treatments. $\ldots \ldots \ldots \ldots \ldots \ldots \ldots \ldots \ldots$ & 1 & 34.9706 & 11.07 \\
\hline Error $\ldots \ldots \ldots \ldots \ldots \ldots$ & 102 & 3.1580 & $\ldots \ldots$ \\
\hline
\end{tabular}

* Adjusted by covariance for yield of 1933-34.

† A value of 6.64 indicates a probability of 99 to 1 .

The distribution of the gross returns, by sizes and grades, is given in figure 4. Under the heading "Standards and culls" are included gross returns for all fruits of these grades and also the returns for unpacked Fancy and Choice fruits of small size. The actual costs of picking and hauling are indicated. The net return to the grower for fruit on the trees was found to be, from zinc-treated trees, $\$ 2.52$ per tree; and from untreated trees, $\$ 1.56$ per tree.

Although the yield increase was only about 20 per cent, the improvement in fruit size and quality was so great that the net receipts to the grower were increased 61.5 per cent for trees treated with zinc. On the basis of ninety trees per acre, the increased return to the grower

${ }^{6}$ These rates are subject to minor increases due to differences between actual cost of packing and preliminary charges based on estimates. Otherwise, they represent the value of fruit delivered at the packing-house. 
amounted to $\$ 86.40$ per acre in the case of this orchard, moderately affected with mottle-leaf. These returns do not include the cost of zine treatment, which is usually less than $\$ 10.00$ per acre under commercial conditions.

\section{TREES SLIGHTLY AFFECTED WITH MOTTLE-LEAF}

The part of the orchard discussed above includes several guard rows where the trees showed about 5 to 10 per cent of mottle-leaf foliage in

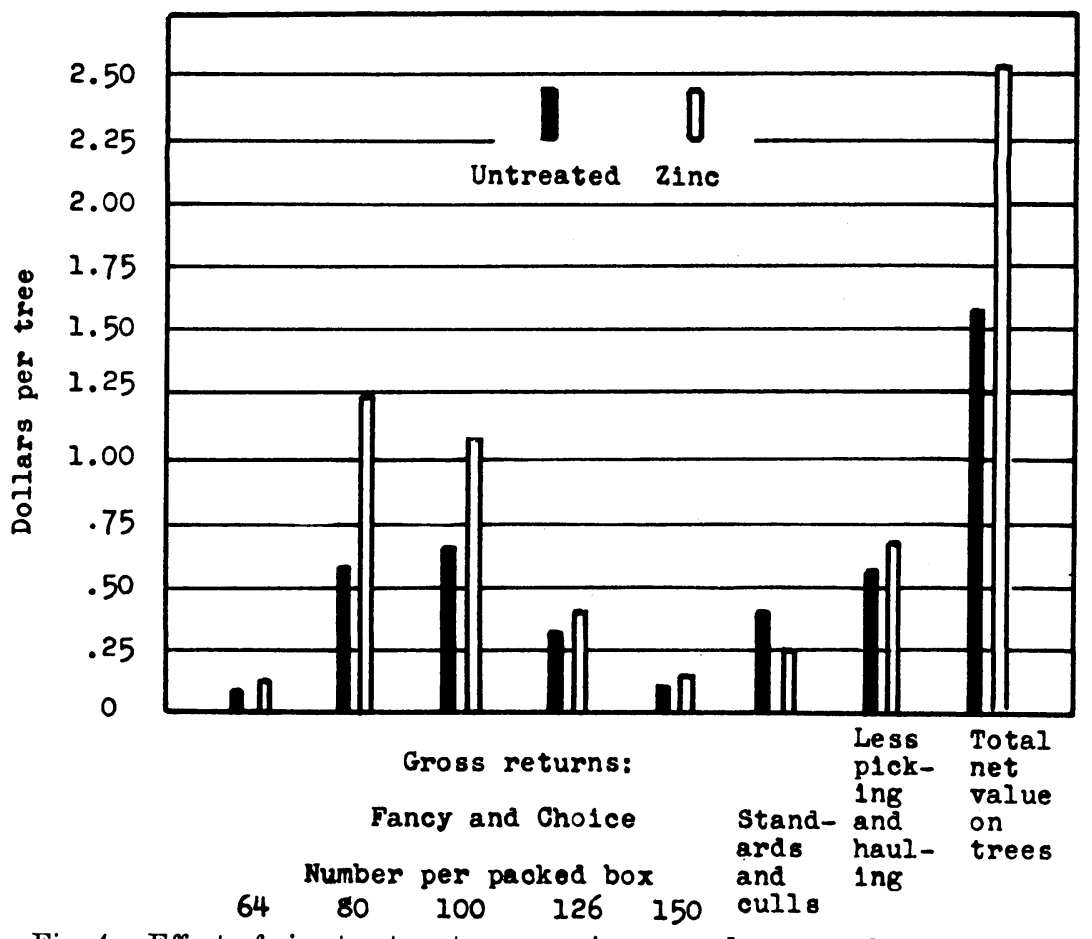

Fig. 4.-Effect of zine treatment on gross income and on net value of fruit on the trees; grapefruit, 1934-35 season.

March, 1934. These trees were the best in the orchard at that time. Although no definite effects of mottle-leaf could be seen on the fruits, it seemed desirable to determine if zinc treatment in March, 1934, affected the yield of the trees in the 1934-35 crop. Twenty-six rows were selected for study. These had received liberal applications of organic matter in the fertilizer program. The fertilizer consisted of dairy manure in such amount that 1 pound or more of nitrogen was annually applied from this source on one side of the tree and $1 / 2$ pound or more from the same source on the other side. 
The yield data in 1934-35 were adjusted on the basis of the yields in 1933-34, the year before the zinc treatment. Fisher's (1936) methods of covariance were used. The results of the analysis of the adjusted yields are given in table 2. The value of $F$ (Snedecor, 1934) was found to be 11.07, which indicates a probability greater than 99 to 1 (for which $F=6.64$ ) that zinc treatment increased yields of these slightly affected trees. The mean adjusted yields per tree are given in table 3 and show that, although significant, the yield increase as a result of zinc treatment was only 10.75 per cent. Evidently very mild symptoms of mottleleaf are accompanied by only slight decreases of yield.

TABLE 3

Mean Adjusted Yields for 1934-35 of Grapefrutt Trees Slightly Afrected With Mottle-Leaf When SubJected to Zinc Treatment at the Beginning of the Blooming Period

\begin{tabular}{|c|c|c|}
\hline & $\underset{\substack{\text { Number } \\
\text { of trees }}}{\text { Non }}$ & $\begin{array}{l}\text { Mean adjusted } \\
\text { yield per tree, } \\
\text { field boxes* }\end{array}$ \\
\hline $\begin{array}{l}\text { Zine treated } \\
\text { Untreated..... }\end{array}$ & $\begin{array}{l}78 \\
52\end{array}$ & $\begin{array}{r}10.92 \\
9.86\end{array}$ \\
\hline
\end{tabular}

* Approximately 43 pounds each, net.

\section{TREES VERY SEVERELY AFFECTED WITH MOTTLE-LEAF}

There were in March, 1934, two guard rows in the orchard that contained grapefruit trees which were very severely affected with mottleleaf. The fruit of the five grapefruit trees in each of these rows is not included in the foregoing analyses of the remainder of the crop. Practically all of the leaves in the trees showed the typical symptoms of partial chlorosis, small size, and lack of vigor. The green parts of many leaves were dull green in color and the leaves were thickened. Twig growth was short and the trees presented an open, unthrifty appearance. For a number of years the yields of the trees had been observed to be below average, but no actual records exist for several years prior to the 1933-34 crop. The quality of the fruit also had been very poor. A description of the fruit is given in a later section.

Treatment in March, 1934, of three trees in each of the two rows, with the spray mixture of zinc sulfate and hydrated lime previously described, resulted within a few weeks in pronounced improvement of the foliage. In contrast with the two untreated trees in each row, the old leaves on the treated trees became more normal in color, although they 
did not grow. However, in 1934 the spring cycle of growth on treated trees was normal. The leaves were large, lush, and of excellent color. Twig growth was vigorous. The blossoms produced at the normal blooming period were larger and more vigorous, but not more numerous than on the untreated trees. The improved condition and growth of the treated trees were maintained throughout the crop year, whereas the

TABLE 4

Yields of Individual Trees Severely Afrected with Mottle-Leaf in Year Prior to Treatment with Zinc, and in Year of Treatment

\begin{tabular}{|c|c|c|c|c|}
\hline \multirow{3}{*}{ Treatment } & \multirow{3}{*}{ Tree No. } & \multicolumn{3}{|c|}{ Yield, in field boxes* } \\
\hline & & \multirow{2}{*}{$\underset{1933-34}{\text { Preliminary, }}$} & \multicolumn{2}{|c|}{ Experimental, 1934-35 } \\
\hline & & & Unadjusted & Adjusted $\dagger$ \\
\hline \multirow{5}{*}{ Untreated.. } & $\mathrm{H}-21-7 \ldots$ & 0.9 & 1.2 & 1.72 \\
\hline & H-21-9. & 2.5 & 2.4 & 2.26 \\
\hline & H-29-7. . & 0.3 & .02 & .79 \\
\hline & H-29-9. & 1.3 & 1.5 & 1.86 \\
\hline & Mean.. & 1.25 & 1.28 & 1.66 \\
\hline \multirow{7}{*}{ Zinc-treated... } & H-21-1 $\ldots$ & 4.0 & 9.4 & 8.64 \\
\hline & $\mathrm{H}-21-3 \ldots$ & 3.4 & 10.0 & 9.49 \\
\hline & $\mathrm{H}-21-5$ & 2.0 & 12.5 & 12.57 \\
\hline & $\mathrm{H}-29-1$. & 6.4 & 13.7 & 11.95 \\
\hline & H-29-3.. & 0.4 & 10.3 & 11.03 \\
\hline & H-29-5. & 0.4 & 10.6 & 11.33 \\
\hline & Mean & 2.77 & 11.08 & 10.83 \\
\hline
\end{tabular}

* Of approximately 43 pounds each, net.

$\dagger$ Adjusted for preliminary yield and with row variation eliminated.

untreated trees were not vigorous and their condition remained poor.

Yields.-The yields of the severely affected trees in 1934-35 have been adjusted by covariance on the basis of their individual yields in the previous year. Variation due to differences between rows was also eliminated in the analysis of variance. The unadjusted yields and the adjusted yields are presented in table 4 on a volume basis.

Evidently the zinc treatment greatly increased the yields in the season of treatment. The average increase in adjusted yield was found to be 552 per cent of the yield of the check trees in that year. The reliability of the increase is shown by the analysis of variance of the adjusted yields as given in table 5. The $F$ value, 102.8, indicates that the effect of treatment has been significant with a probability much greater than 99 to 1 (for which $F=13.72$ ). The actual increase is very much greater than that resulting from the treatment of the trees in a relatively less 
severely mottled condition. A comparison with the yields in 1934-35 of the trees least affected with mottle-leaf (table 3), shows that the severely affected trees, upon treatment, yielded approximately equal amounts of fruit. These results indicate, therefore, that the effects of mottle-leaf upon the yield are correlated with the severity of the dis-

TABLE 5

Analysis of Variance of Adjusted Yields in 1934-35 of Grapefruit Trees Severely Affected with Motrle-Leaf; Treatment in March, 1934

\begin{tabular}{|c|c|c|c|}
\hline Source of variation & $\begin{array}{l}\text { Degrees of } \\
\text { freedom }\end{array}$ & $\begin{array}{l}\text { Adjusted mean } \\
\text { square }\end{array}$ & $F^{*}$ \\
\hline Total. & 9 & 23.8211 & $\ldots$ \\
\hline Between rows........ & 1 & 0.5174 & $\ldots \ldots$ \\
\hline Between treatments...... & 1 & 202.0793 & 102.81 \\
\hline 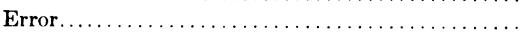 & 6 & 1.9656 & $\ldots \ldots$ \\
\hline
\end{tabular}

${ }^{*}$ For a probability of 99 to $1, F=13.72$.

TABLE 6

Size of Fruits Harvested in Crop of 1934-35 from Individual Grapefruit Trees Severely Affected with Motthe-Leaf ; Treatment March, 1934

\begin{tabular}{|c|c|c|}
\hline Treatment & Untreated & Zinc-treated \\
\hline $\begin{array}{l}\text { Number of fruits per tree, range } \ldots \ldots \ldots \ldots \ldots \\
\text { Number of fruits per field box, range........ } \\
\text { Mean diameter of fruits, mm, range } \ldots \ldots \ldots \ldots \\
\text { Coefficient of variability of diameter in per } \\
\text { cent of mean, range..................... }\end{array}$ & $\begin{array}{c}3 \text { to } 220 \\
91.7 \text { to } 103.3^{*} \\
65.33 \pm 0.092 \text { to } 75.00 \pm 0.882 \\
18.56 \text { to } 26.04\end{array}$ & $\begin{array}{c}537 \text { to } 806 \\
52.1 \text { to } 64.5 \\
84.88 \pm 0.198 \text { to } 92.86 \pm 0.286 \\
7.07 \text { to } 10.62\end{array}$ \\
\hline
\end{tabular}

* Omitting tree H-29-7, which matured only 3 fruits.

order, and that zine treatment removed or alleviated a factor which was limiting the yields of affected trees.

Fruit Size.-At the time of harvesting the 1934-35 crop of fruit from the severely mottled trees, the diameter of all individual fruits was determined. The data so secured have been grouped into frequency distributions with a class interval of $10 \mathrm{~mm}$. The per-tree means of the values for each class are presented in figure 5. A striking increase in the number of fruits harvested per tree was obtained as a result of zinc applications.

The proportion of desirable large and medium-sized fruit was also increased. Since the fruit packed at the rate of 150 fruits per box has a minimum diameter of $80 \mathrm{~mm}$, the data of figure 5 show that the larger part of the crop of treated trees was of desirable size. An increase in the average size of fruit is further shown by the data in table 6 , where 
the range in size of fruit for individual trees is interpreted in number of fruits per field box, and also in actual diameters.

The fruit from the zinc-treated trees was also the more uniform. This is indicated by the smaller coefficients of variability in the case of the fruit from the treated trees.

Grade of Fruit.-No quantitative determination of the grade based on external appearance was made on fruits from the severely mottled

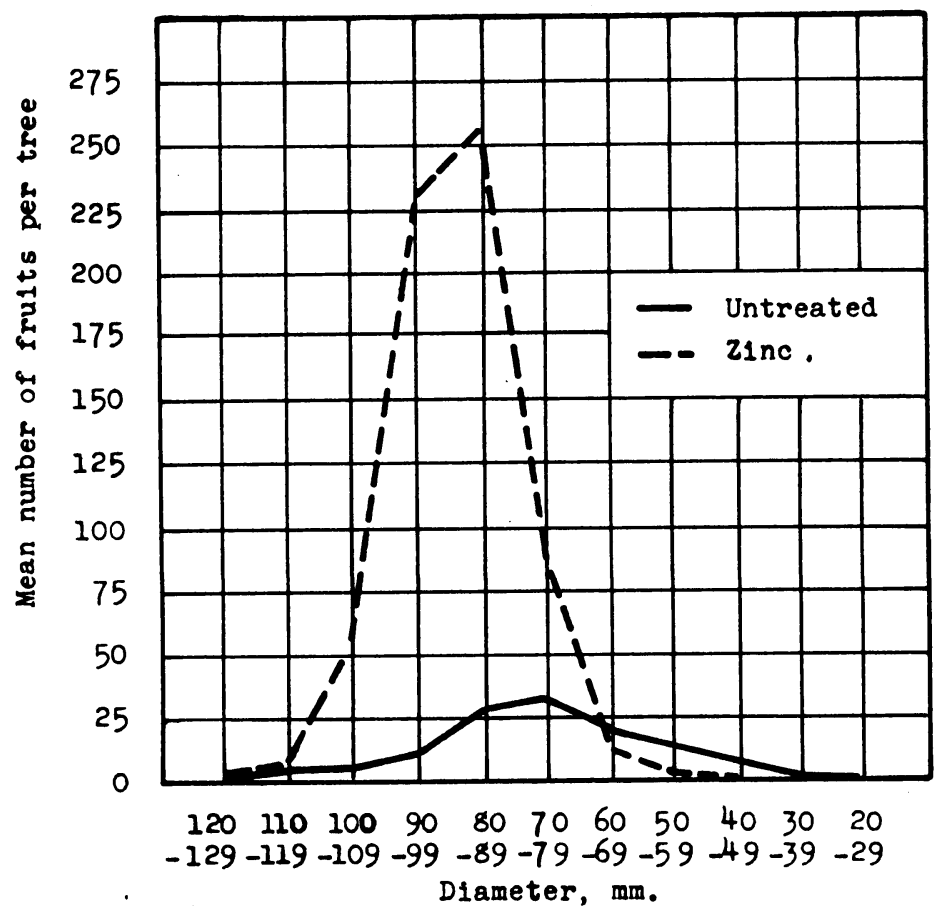

Fig. 5.-Size distribution of grapefruits from trees severely affected with mottle-leaf.

grapefruit trees. However, the fruits from the untreated trees would have been almost entirely culled out in commercial grading, owing to undesirable color, texture, shape, or blemishes. Many of the fruits were too small to pack. Measurement of all the fruit indicated that the proportion smaller than $80 \mathrm{~mm}$ diameter (150 per packed box), was 15.20 per cent from zinc-treated trees, and 64.27 per cent from untreated trees.

Many fruits from the more severely affected branches of untreated trees were also abnormal in shape. Sectioning showed that some locules were undeveloped. Frequently resinlike deposits in the albedo were 


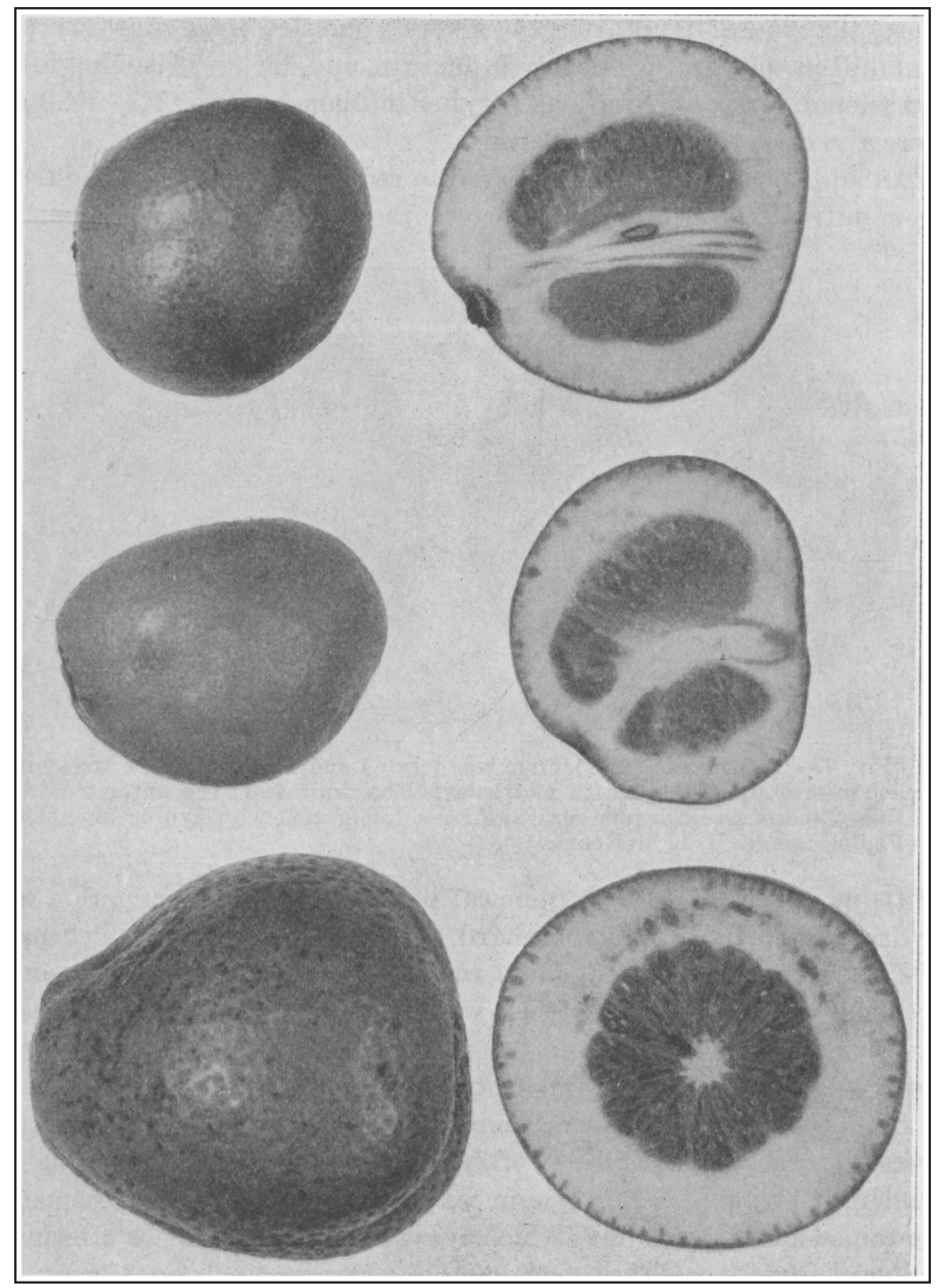

Fig. 6.-Abnormal grapefruits $(\times 3 / 4)$ from trees severely affected with mottle-leaf. 
observed. These varied from about a millimeter in diameter to relatively large size. Such abnormalities are illustrated in figure 6 . Furthermore, the rind of fruit from the severely mottled trees was very pale and dull in color, rather pebbly in texture, and dry, as if lacking in oil. Occasional dark discolorations varying in diameter from 0.5 to $4.0 \mathrm{~mm}$ were also observed in the epidermis.

An additional factor was observed to reduce the quality of the fruits from untreated trees. This was the occurrence of a considerable number

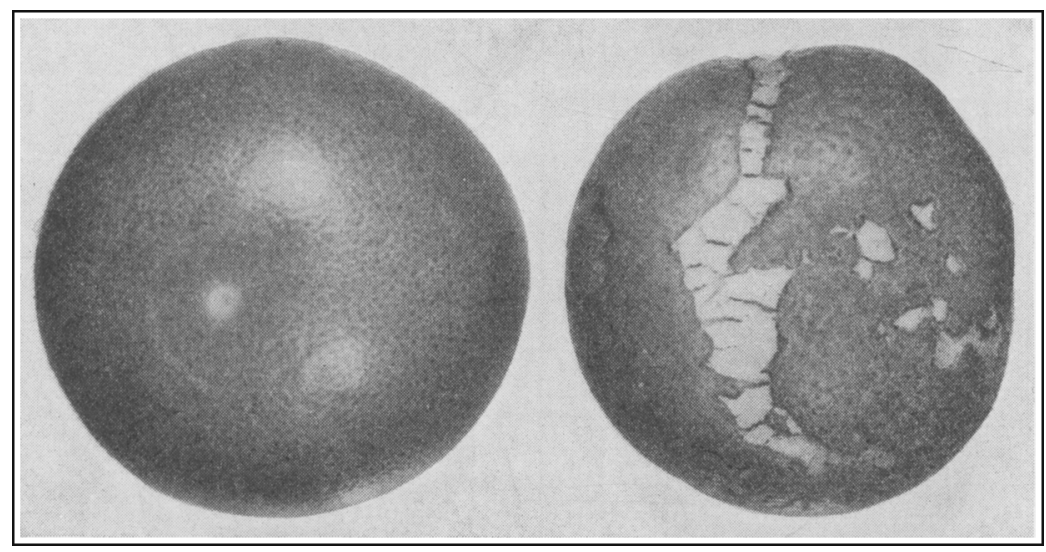

Fig. 7.-Grapefruits $(\times 3 / 4)$ from zinc-treated and from untreated trees previously severely affected with mottle-leaf. The fruit from the untreated tree (right) shows severe injury resulting from fumigation with hydrocyanic acid. (Photograph by H. L. McKenzie.)

of fruits which showed symptoms of injury caused by fumigation with hydrocyanic acid gas. The orchard had been fumigated in February, 1935, as a routine pest-control operation. Although the injury was most frequent on very small fruits, it was observed that fruits of the same size were more susceptible on the untreated trees (fig. 7). Fumigation injury did not occur on fruits of treated trees.

Rind Characteristics.-Sectioning the fruits from severely mottled trees showed that the albedo of fruits from untreated trees was less tender; it was abnormally fine in texture. Also, these fruits frequently contained small, hard areas which appeared to be filled with a resinlike material (fig. 6).

The rind from untreated trees appeared abnormally thick, in comparison with that of the treated trees (fig. 8). To determine if this was so, about 25 fruits of each of several sizes were selected from both classes of trees. The fruits chosen were within $1 \mathrm{~mm}$ of 40,50,60,70, 80, 90, and $100-\mathrm{mm}$ diameter. Fruits of normal shape were selected, but other 


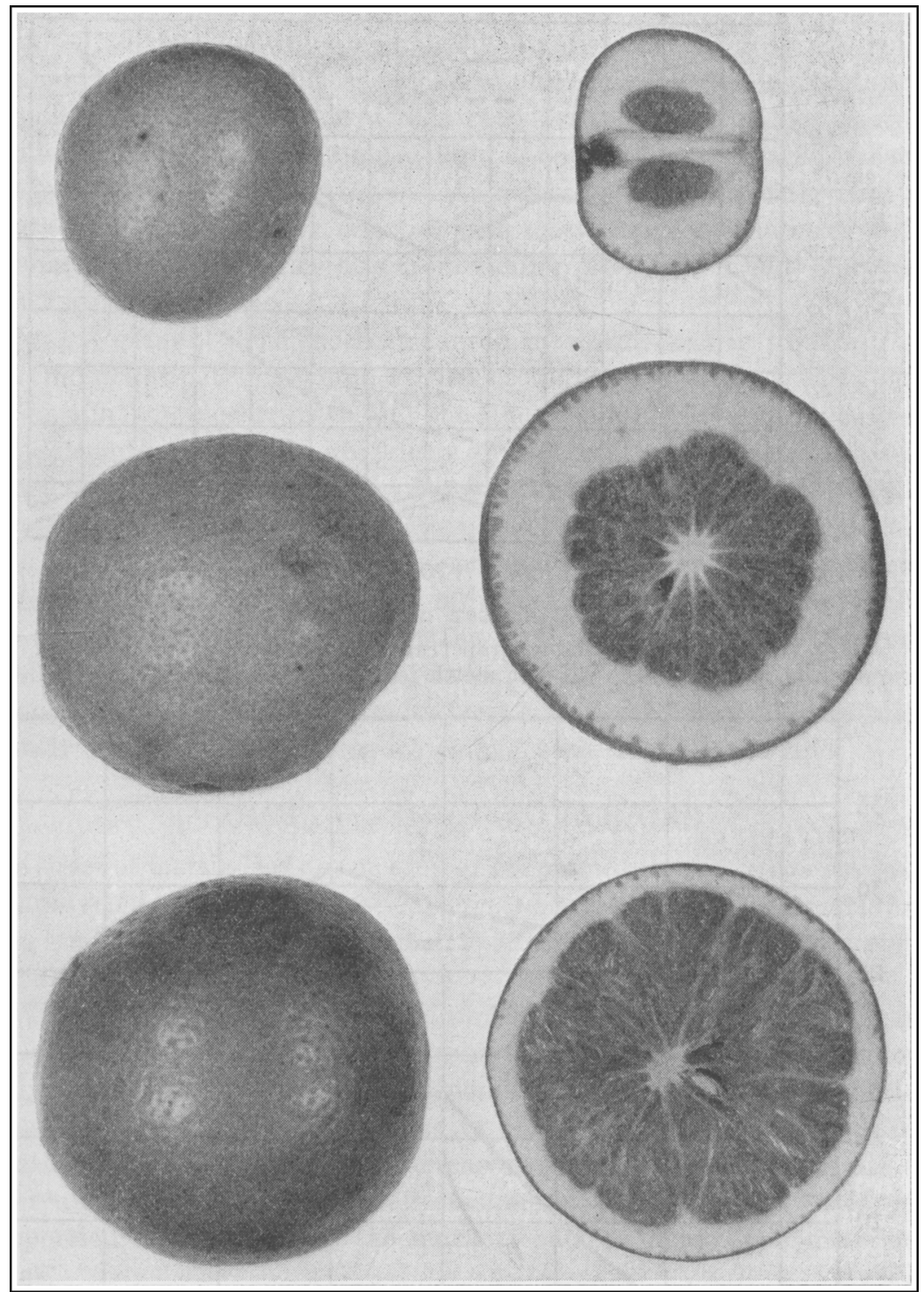

Fig. 8.-Fruits $(\times 3 / 4)$ from grapefruit trees severely affected with mottleleaf. The two fruits at the bottom are from trees which were sprayed with a mixture of zine sulfate and hydrated lime at blooming time. The other fruits are from comparable untreated trees. The two fruits at the top were produced on branches exhibiting extreme symptoms. 


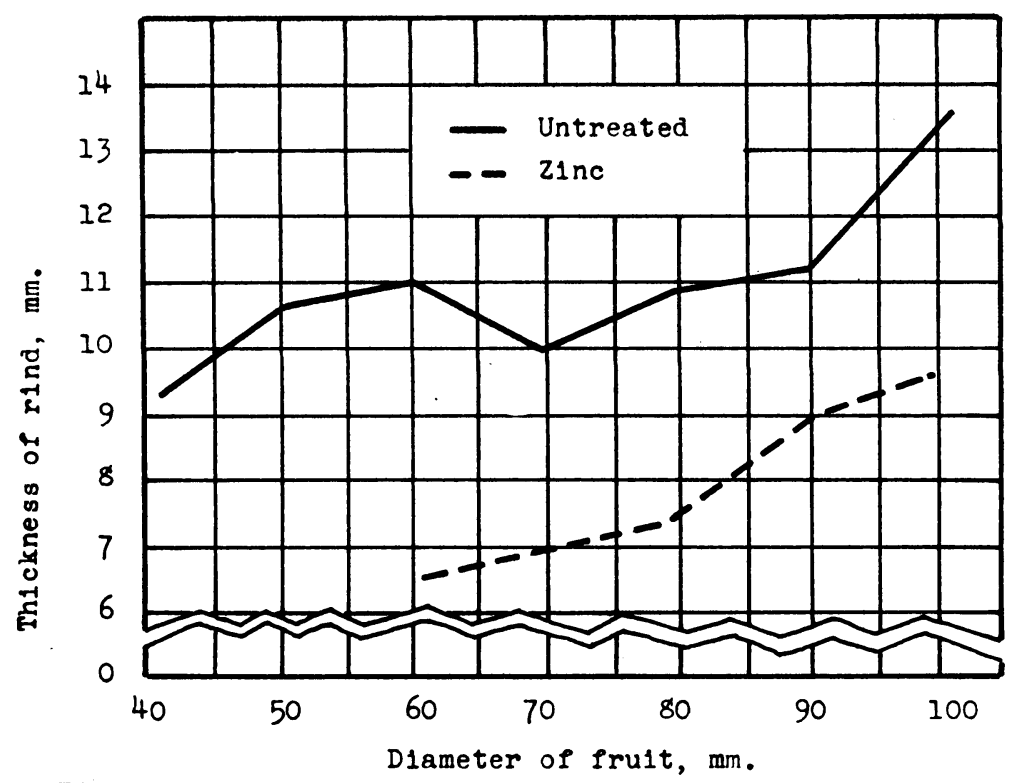

Fig. 9.-Thickness of rind of grapefruits from trees severely affected with mottle-leaf.

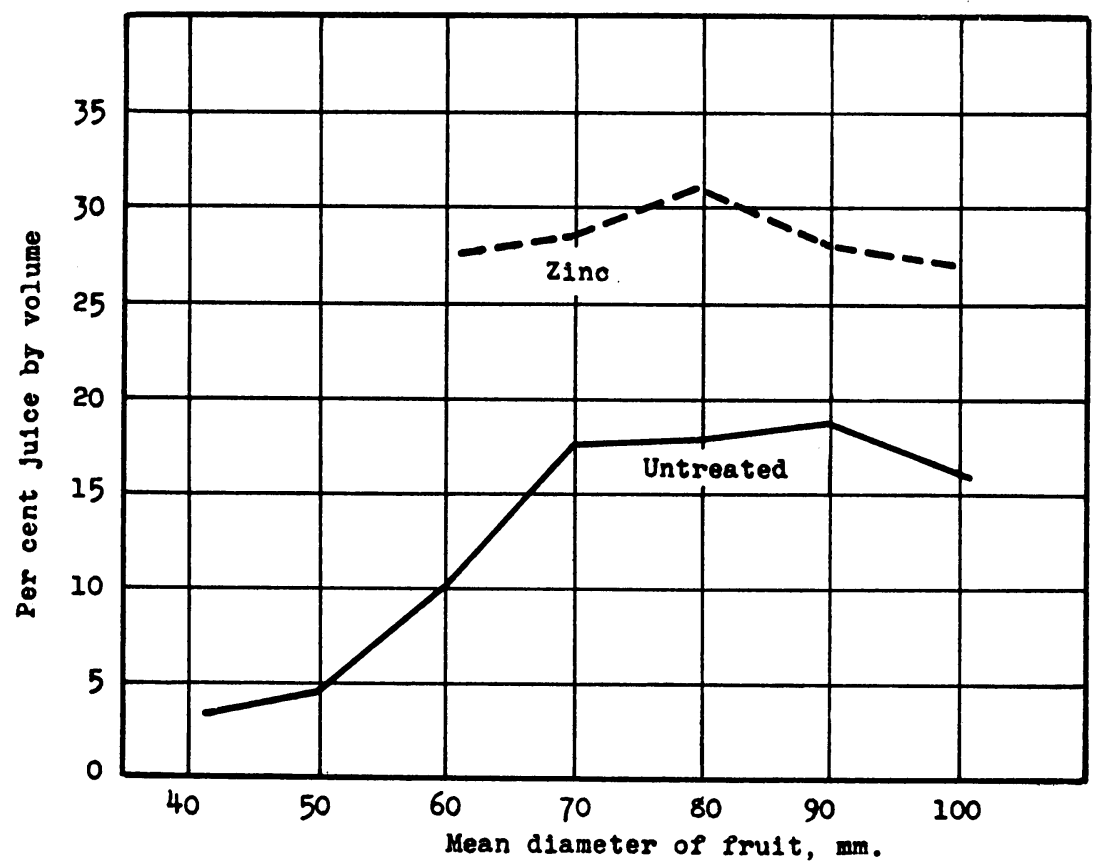

Fig. 10.-Juice content of grapefruits from trees severely affected with mottle-leaf. 
characteristics were not considered. Comparisons were made between fruits from zinc-treated and untreated trees for all sizes except 40 and $50 \mathrm{~mm}$ diameter, for which insufficient numbers existed from the zinctreated. Measurements of the thickness of the rind at the mid-point of a typical locule were made with a responsive vernier caliper having slender, pointed jaws. The mean figures obtained are shown for each size in figure 9. The results indicated a marked thickening of the rind of fruits from trees severely affected with mottle-leaf, as compared with normal fruits of the same size from similar trees which had, however, been treated with zinc.

Juice Content.-The increase caused by mottle-leaf in thickness of the rind of grapefruits would appear to reduce the edible portion and the amount of juice in the fruit. The juice content of the fruits cut for the determination of the thickness of the rind was, therefore, determined. The fruit was reamed by hand, and the juice strained through a wire screen of $1.7-\mathrm{mm}$ mesh. The volume of the fruit had previously been determined by an immersion method. The mean quantity of the juice of fruits of various sizes is indicated in figure 10, where results are expressed as a percentage of the total volume of fruit. The very small fruits from untreated mottle-leaf trees had an extremely small amount of juice, and larger fruits from such trees had much less juice than fruits from similar trees which had been treated with zine.

\section{SUMMARY AND CONCLUSIONS}

The effect of mottle-leaf on the crop of grapefruit trees (Citrus paradisi Macfadyen) and the response of affected trees to zinc treatment has been studied. Mottle-leaf was found to affect greatly both the total yield and the quality of the crop.

When treated with a zinc-containing spray at the start of the blooming period, a typical grapefruit orchard which was previously moderately affected with mottle-leaf responded in the first season. Normal growth resulted, with an increase in the crop set immediately after treatment. Fruit size was also increased, and the commercial grade of the fruit was improved. These effects resulted in acceptance of a larger proportion of the crop by the markets and in increased commercial value.

The best trees in this orchard, only slightly affected with mottle-leaf, responded to zinc treatment by producing only slightly more fruit than similar but untreated trees.

However, trees very severely affected with mottle-leaf responded most strikingly to treatment. The growth and foliage characteristics became 
normal within a few weeks after the application of the spray. The crop produced in the season after treatment was increased several hundred per cent, and was about equal to the crop produced by healthy trees. The quality of the fruit was also greatly improved by treatment. In contrast to the severely affected untreated trees, the fruit produced by comparable treated trees was of normal size and shape and had more pleasing exterior characteristics. Resinlike formations in the albedo were lacking. Such fruit had thinner rind and contained more juice than did the fruit from the severely mottled and untreated trees. Injury from hydrocyanic acid fumigation was suffered by small fruits produced on the trees severely affected by mottle-leaf, but not by fruits of equal size on the treated trees.

It appears that mottle-leaf has a profound effect on the fruiting behavior of grapefruit trees. Affected trees respond very readily to suitable treatment of the foliage with zinc-containing sprays.

The degree of response as measured by the quantity and quality of the crop produced was found to be related to the severity of the symptoms, all treated trees apparently losing for a time the symptoms of mottle-leaf and the cropping limitations imposed by it. The results are in accord with the view that zinc treatment is specific for mottle-leaf. They suggest that, in the absence of leaf symptoms, zinc treatment will have little, if any, effect on the size and quality of the crop produced. 


\section{LITERATURE CITED}

Batchelor, L. D., E. R. Parker, and R. McBride.

1928. Studies preliminary to the establishment of a series of fertilizer trials in a bearing citrus grove. California Agr. Exp. Sta. Bul. 451:1-49. (Out of print.)

Chandler, W. H., D. R. Hoagland, and P. L. Hibbard.

1931. Little-leaf or rosette in fruit trees. Amer. Soc. Hort. Sci. Proc. 28:556-60. 1932. Little-leaf or rosette in fruit trees. II. Effect of zine and other treatments. Amer. Soc. Hort. Sci. Proc. 29:255-63.

Fisher, R. A.

1936. Statistical methods for research workers. 6th ed. 339 p. Oliver and Boyd, London.

FAWCETT, H. S.

1936. Citrus diseases and their control. 2nd ed. 656 p. MeGraw-Hill Book Co., New York City.

Johnston, J. C.

1933. Zine sulfate promising new treatment for mottle-leaf. California Citrograph $18: 107,116$.

1934. Experiments in mottle-leaf control. California Citrograph 19:148, 159.

1936. Effect of mottle-leaf on fruit size. California Citrograph 22:86-87.

Mowry, H., and A. F. CAMP.

1934. A preliminary report on zine sulfate as a corrective for bronzing of tung trees. Florida Agr. Exp. Sta. Bul. 273:1-34.

PARKer, E. R.

1934. Experiments on the treatment of mottle-leaf of citrus trees. Amer. Soc. Hort. Sci. Proc. 31:98-107.

1936. Experiments on the treatment of mottle-leaf of citrus trees. II. Amer. Soc. Hort. Sci. Proc. 33:82-86.

1937. Experiments on the treatment of mottle-leaf of citrus trees. III. Amer. Soc. Hort. Sci. Proc. 34:213-15.

REed, H. S., and J. Dufrénox.

1935. Modification in cell structure accompanying mottle-leaf of the orange. Amer. Jour. Bot. 22:311-18.

REed, H. S., and E. R. PARKer.

1936. Specific effects of zinc applications on leaves and twigs of orange trees affected with mottle-leaf. Jour. Agr. Research 53:395-98.

SNEDECOR, G. W.

1934. Calculation and interpretation of analysis of variance and covariance. $96 \mathrm{p}$. Collegiate Press, Inc., Ames, Iowa. 
